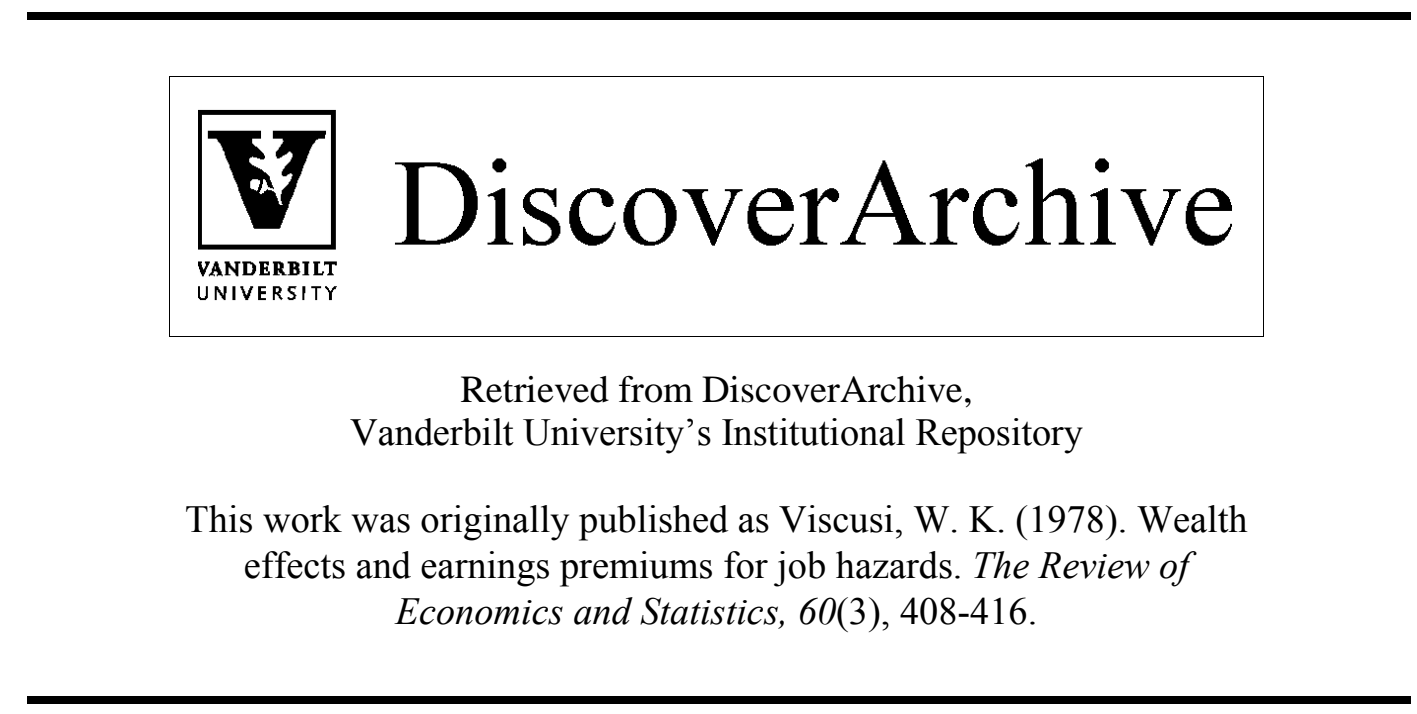




\title{
WEALTH EFFECTS AND EARNINGS PREMIUMS FOR JOB HAZARDS
}

\author{
W. Kip Viscusi*
}

\section{Introduction}

A DAM Smith (1937) observed that "the whole of the advantages and disadvantages of the different employments of labor and stock must, in the same neighborhood, be either perfectly equal or continually tending to equality." If a job poses health and safety risks that are especially great, a worker will require higher levels of compensation or greater non-pecuniary benefits in order for him to accept the risky job. Despite the fact that the theory of compensating differentials is almost two centuries old, it has been only recently that this theory has been subjected to successful empirical tests. ${ }^{1}$

The purposes of this essay are twofold. First, in section II, I will formalize the theory of individual choice among potentially hazardous jobs for the general situation in which worker preferences are contingent on the health state outcome. An important implication of this analysis is that the job risk that a worker selects will be negatively related to his wealth. The second purpose of the investigation is to test the two principal conceptual hypotheses. The characteristics of the principal data source to be ùsed are summarized in section III. The University of Michigan Survey of Working Conditions, which is the data set used in the compensating differentials analysis, provides very extensive information concerning the nature of the worker's particular job and his personal characteristics. Section IV presents the analysis of the earnings differentials generated

Received for publication November 29, 1976. Revision accepted for publication May 20, 1977.

* Northwestern University.

Professors Kenneth Arrow, Richard Freeman, Richard Zeckhauser, and an anonymous referee provided helpful comments. The U.S. Department of Labor provided financial support. This essay is adapted from Viscusi (1976).

${ }^{1}$ The recent investigations by Smith (1976) and by Thaler and Rosen (1976) consider wage premiums for death risks faced by workers. An earlier study of skill differentials is that of Reder (1962). by job hazards and other job attributes. In section V, I consider the responsiveness of the job risk to a worker's wealth. The empirical findings, which are consistent with the theoretical predictions, are summarized in section VI.

\section{Optimal Choice among Hazardous Job Alternatives}

Recent economic analyses of choices among potentially hazardous jobs have generalized Adam Smith's notion of compensating wage differentials to probabilistic contexts. The study by Oi (1973) views adverse job consequences as being tantamount to a drop in income. He concludes that jobs posing greater risks will command compensating wage differentials. A more detailed analysis along similar lines is presented by Thaler and Rosen (1976), who develop Oi's approach and also consider the situation in which individuals face lotteries on life and death. ${ }^{2}$ The payoff after an adverse outcome (death) is represented by a bequest function. The approach taken here also can be viewed as a probabilistic generalization of the compensating differential analysis. It differs in that individuals' utility functions are assumed to be dependent on one's health state. The static model in this section illustrates the properties of the optimal job choice of a worker who is choosing from a set of job opportunities that involve the same number of work hours but have differing probabilities of an adverse consequence. ${ }^{3}$ This approach does not impose assumptions that are unduly restrictive since most job opportunities offer little individual leeway in the choice of hours.

\footnotetext{
${ }^{2}$ Thaler and Rosen (1976) also set up, but do not fully develop, a more general model in which there are $N$ possible outcomes.

${ }^{3}$ Theoretically, there is little that can be said about a fully generalized multi-attribute case that does not represent a straightforward extension of this simple model. Perhaps the most important implication of a generalized model is that a worker should be cognizant of the entire portfolio of risky actions and should not make piecemeal decisions when strong interdependencies are involved.
} [408] 
For simplicity, assume that there is no income uncertainty associated with any particular job. Although the wage rate is known, the health state resulting from one's activities is determined probabilistically. In this simple model, one's health does not affect one's earnings. Two health states will be considered. State 1 refers to good health, while state 2 refers to ill health, such as being injured. The individual's objective is to select the job that maximizes his expected utility.

This formulation of worker preferences permits the marginal utility of consumption (or alternatively of wealth) to differ according to one's health status. An alternative approach of using a conventional utility function that depends on wealth alone could be employed in the job injury context by viewing an injury as being tantamount to a drop in wealth. However, if utility functions are assumed to be of the usual concave form, this formulation would imply that the marginal utility of income is less when a person is healthy than when he is not.

The shortcomings of this approach become particularly apparent if actuarially fair income insurance is available. Workers will, of course, equate the marginal utility of income in the two possible states. In a model in which health and safety impacts have monetary equivalents, the absolute level of the individual's welfare will be identical irrespective of the job outcome. If, however, worker utility functions are allowed to vary according to the worker's health, such a result need not occur, as lower welfare levels for the unhealthy state may result. ${ }^{4}$

The notation to be used in analyzing the worker's choice problem is summarized below:

$u^{j}=$ the utility function in health state $j$, where $j=1,2$;

$x=$ the composite consumption good whose price equals one;

$p=$ the probability of the unattractive state 2 occurring;

$w(p)=$ the wage for a job offering probability $p$ of state 2 occurring;

\footnotetext{
${ }^{4}$ If the marginal utility of consumption is lower in the injured state, as is plausible, workers faced with actuarially fair insurance possibilities will have a lower absolute welfare level in the injured state when the marginal utility of consumption is equated for the two states.
}

$$
\begin{aligned}
A & =\text { initial assets; } \\
\lambda & =\text { the shadow price of the goods con- } \\
& \text { straint. }
\end{aligned}
$$

Letter subscripts on the $u^{j}$ and $w$ terms indicate partial derivatives. The $u^{j}$ 's and $w(p)$ functions are assumed to be continuous and twice differentiable. The wage schedule $w(p)$ represents the highest wage available for a job with probability $p$ of injury. ${ }^{5}$ The worker receives the same wage for his job irrespective of the actual health impact. The possibility of purchasing insurance has been excluded in the interest of analytic implicity. ${ }^{6}$ It should be noted, however, that non-discretionary insurance benefits, such as workmen's compensation, are not omitted since the state-dependent utility functions encompass influences such as these.

Suppose that workers must select from a range of job alternatives that are equally attractive in terms of their time allocations but which offer different probabilities of unfavorable state 2 occurring. This range is assumed to be continuous and to span all values of $p$. The set of alternatives that must be considered can be restricted to the efficient set of jobs that offer the highest value of $w$ for any value of $p$. The worker's optimal choice from among the market alternatives is determined by maximizing the Lagrangian given by

$$
L=(1-p) u^{1}(x)+p u^{2}(x)+\lambda[x-A-w(p)] .
$$

The job with the optimal risk $p$ is determined by solving the following first-order conditions for a maximum (as well as the budget constraint):

$$
L_{x}=0=(1-p) u_{x}^{1}+p u_{x}^{2}+\lambda,
$$

and

$$
L_{p}=0=-u^{1}+u^{2}-\lambda w_{p} .
$$

Solving for $w_{p}$ produces the result

$$
w_{p}=\frac{u^{1}-u^{2}}{(1-p) u_{x}^{1}+p u_{x}^{2}}>0 \text {. }
$$

${ }^{5}$ For this static formulation, it does not matter whether $p$ is uncertain or known with precision. The compensating differential results generalize with some modification to multiple periods and instances in which there is worker learning. See Viscusi (forthcoming).

${ }^{6}$ The analysis of the role of insurance is presented in Viscusi (1976). 
The necessary condition for an interior maximum is that a marginal increase in the wage as a result of the increased job risk be positive and equal to the difference in the two states' utilities divided by the expected marginal utility of consumption. ${ }^{7}$ Thus the job market equilibrium function $w(p)$ is necessarily an increasing function of $p$ if workers are employed at each level of $p$. Jobs with identical stochastic properties will be rewarded equally in equilibrium. ${ }^{8}$ The positive sign of $w_{p}$ is a result of the nature of the job choice problem. It is not an assumption. The derivation of this result did not require that workers be risk averters. The only key assumption required was that the good health state be more desirable than the ill health state. ${ }^{9}$

To assure that a solution to equation (3) is indeed a maximum, the second-order condition also must be fulfilled. In mathematical terms, the marginal rate of change of $w_{p}$ with respect to further increases in $p$ must be either negative of consumption is diminishing (i.e., $u_{x x}^{1}<0$ and $u_{x x}^{2}<0$ ) and that the marginal utility of consumption is greater in the healthy state than in the injured state (i.e., $u_{x}^{1}>u_{x}^{2}>0$ ).

This model can also be profitably applied to ascertain the influence of one's initial wealth on the level of job hazards one will select. The positive relationship between individual wealth and the attractiveness of the nonmonetary attributes of one's job has long been noted by labor market analysts, such as Reder (1962). This relationship was recently analyzed by Weiss (1976)' and Thaler and Rosen (1976). Results in a similar vein can be obtained under somewhat different assumptions within the context of the health state model of job choice.

To determine the relationship of one's assets to the optimal probability of injury, one can totally differentiate the first-order conditions (equations (1) and (2) and the budget constraint), and solve for $d p / d A$ using Cramer's rule, producing the result that

$$
\frac{d p}{d A}=\frac{-\left[(1-p) u_{x x}^{1}+p u_{x x}^{2}\right] w_{p}-\left[u_{x}^{2}-u_{x}^{1}\right]}{w_{p}^{2}\left[(1-p) u_{x x}^{1}+p u_{x x}^{2}\right]+2 w_{p}\left[u_{x}^{2}-u_{x}^{1}\right]+w_{p p}\left[p u_{x}^{2}+(1-p) u_{x}^{1}\right]}
$$

or positive, but not too large:

$$
\begin{aligned}
w_{p p}<\{ & -\left(w_{p}\right)^{2}\left[(1-p) u_{x x}^{1}+p u_{x x}^{2}\right] \\
& \left.-2 w_{p}\left[u_{x}^{2}-u_{x}^{1}\right]\right\}\left\{p u_{x}^{2}+(1-p) u_{x}^{1}\right\}^{-1} .
\end{aligned}
$$

The right hand side of equation (4) is positive, assuming plausible restrictions on the utility function. In particular, I will assume throughout this section that the marginal utility

\footnotetext{
${ }^{7}$ Throughout the rest of this section, I will consider interior solutions only. The corner solutions are neither realistic nor analytically interesting.

${ }^{8}$ No attempt is made here to provide a detailed discussion of market equilibrium since doing so would duplicate Thaler and Rosen's (1976) analysis.

If one uses a model with a single utility function (not conditional on one's health) in which job risk outcomes are viewed as monetary equivalents, $w_{p}$ is positive so long as $u^{\prime}>0$ and the argument of $u$ is greater when the worker is not injured on the job. This property is quite unrestrictive and implies nothing whatsoever about the risk aversion, or lack thereof, on the part of the worker. For this single-argument case, the worker is said to be risk-averse if $u^{\prime \prime}<0$. The second-order conditions for a maximum impose other restrictions, but do not require risk aversion. For simplicity, I will assume that the marginal utility of consumption is diminishing.
}

Since the numerator is clearly positive, the sign of $d p / d A$ is the same as that of the denominator. Hazardous jobs will be an inferior occupational pursuit, as is plausible, if

$$
\begin{aligned}
& w_{p}^{2}\left[(1-p) u_{x x}^{1}+p u_{x x}^{2}\right]+2 w_{p}\left[u_{x}^{2}-u_{x}^{1}\right] \\
& +w_{p p}\left[p u_{x}^{2}+(1-p) u_{x}^{1}\right]<0 .
\end{aligned}
$$

But if this equation is solved for $w_{p p}$, the condition reduces to equation (4) - the secondorder condition for a maximum. Consequently, the extent of the job hazard one chooses necessarily decreases with one's wealth. The problem features guaranteeing this result are the requirements that the worker be at an interior maximum and that the utility function satisfy the seemingly mild restrictions specified in the discussion of the second-order conditions.

\section{The Sample and the Variables}

The data source for my investigation of compensating differentials is the 1969-70 University of Michigan Survey of Working 
TABLE 1.-GEOGRAPHICAL, INDUSTRIAL, AND OCCUPATIONAl Characteristics OF THE SUbSAMPLE

\begin{tabular}{lc}
\hline \hline Variable & $\begin{array}{c}\text { Fraction in } \\
\text { the Sample }^{\mathrm{a}}\end{array}$ \\
\hline Location: & .32 \\
$\quad$ Northeast & .21 \\
Southeast and South-Central & .15 \\
Urban & \\
Industry: & .03 \\
Mining & .11 \\
Construction & .31 \\
Manufacturing Durables & .14 \\
Manufacturing Nondurables & .08 \\
Transportation, Communication & .13 \\
$\quad$ and Other Utilities & .15 \\
Wholesale and Retail Trade & .05 \\
Miscellaneous Services & \\
Public Administration & \\
& \\
Occupation: & .34 \\
Craftsmen, Foremen and Kindred & .17 \\
Workers & .01 \\
Service Workers & .05 \\
Private Household Workers & .43 \\
Laborers & \\
Operatives and Kindred &
\end{tabular}

${ }^{a}$ The standard deviations of these variables are given by $\left(m-m^{2}\right)^{.5}$, where $m$ is the fraction in the sample.

Conditions (SWC). The SWC, which provides the most detailed information available concerning the nature of the individual's job, was a national survey of 1,533 workers that was undertaken from December 1969 to January 1970. Farmers and self-employed workers were excluded from the subsample that I considered since they did not respond to the job characteristic questions. In addition, white collar workers were also excluded from the analysis since the job characteristic questions asked were inappropriate for this group. ${ }^{10}$ There were 496 full-time blue collar workers in the subsample that was analyzed.

As the data in table 1 indicate, the subsample being considered reflects substantial geographical and occupational diversity. The 3 locational categories listed comprise the $0-1$ dummy variable list $L O C A T E$. In terms of industrial distribution, the sample is also fairly representative, as large numbers of manufacturing and service workers were included in the survey. The industrial breakdown given is at an aggregative level. For the empirical analysis, a finer categorization by SIC code for the worker's industry was used to construct a list of

\footnotetext{
${ }^{10}$ Results for the pooled blue collar and white collar sample are reported in Viscusi (1976).
}

TABle 2.-MEans and Standard Deviations of Selected Variables in the Blue Collar Subsample OF THE Michigan SURVEY OF WORKING CONDITIONS

\begin{tabular}{|c|c|c|}
\hline Variable & $\begin{array}{l}\text { Mean or Function } \\
\text { in Sample }\end{array}$ & $\begin{array}{l}\text { Standard } \\
\text { Deviation }\end{array}$ \\
\hline \multicolumn{3}{|c|}{$\begin{array}{l}\text { Personal } \\
\text { Background: }\end{array}$} \\
\hline $\begin{array}{l}\text { AGE } \\
F E M A L E \\
\text { BLACK } \\
\text { EDUC } \\
\text { HEALTH } \\
\text { TENURE }\end{array}$ & $\begin{array}{c}39.71 \\
0.234 \\
0.123 \\
10.30 \\
0.266 \\
9.09\end{array}$ & $\begin{array}{c}13.71 \\
\mathrm{a} \\
\mathrm{a} \\
3.03 \\
0.918 \\
10.03\end{array}$ \\
\hline \multicolumn{3}{|c|}{$\begin{array}{l}\text { Enterprise } \\
\text { Characteristics: }\end{array}$} \\
\hline $\begin{array}{l}\text { SIZE } \\
\text { UNION }\end{array}$ & $\begin{array}{r}562.2 \\
0.492\end{array}$ & $\underset{\mathrm{a}}{915.3}$ \\
\hline \multicolumn{3}{|c|}{ Job Characteristics: } \\
\hline $\begin{array}{l}\text { EARNG } \\
\text { DANGER } \\
\text { INJRATE } \\
\text { SUPER }\end{array}$ & $\begin{array}{c}6809.9 \\
0.522 \\
15.93 \\
0.359\end{array}$ & $\begin{array}{c}2870.7 \\
\mathrm{a} \\
\underset{\mathrm{a}}{9.26}\end{array}$ \\
\hline
\end{tabular}

a The standard deviations of the $0-1$ dummy variables are omitted since they can be computed from their function $m$ in the sample, where the standard deviation is $\left(m-m^{2}\right)^{.5}$.

25 0-1 dummy variables that I will refer to as INDUSTRY. Over three-fourths of the workers were either operatives or craftsmen, foremen, and kindred workers. The first 4 of these occupational categories were used to construct the 0-1 dummy variable list $J O B$.

The characteristics of the key variables used in the subsequent analysis are summarized in table 2 . The personal characteristic information available is comparable to that found in several other large data sets. There is information pertaining to the worker's age $(A G E)$, sex $(F E M A L E)$, race $(B L A C K)$, years of schooling (EDUC), health limitations (HEALTH), marital status (SINGLE), and years of experience with the enterprise (TENURE). Since the survey did not include the worker's hourly wage rate, I will use the annual earnings from the worker's principal job (EARNG) and the natural logarithm of this variable (LOGEARNG) as the two dependent variables of interest. ${ }^{11}$

Close to half of the workers are members of

${ }^{11}$ Differences in worker hours are not of great importance since I focus on full-time workers and include an overtime work variable. The absence of a weeks worked variable prevents the construction of a wage variable. 
a union (UNION). Although this fraction is double the nationwide average for the work force as a whole, it does not appear disproportionately large for the blue collar, non-farm population.

The most distinctive feature of the data set is the extensive information pertaining to the worker's job: number of employees at the enterprise (SIZE), union membership ( $U N$ $I O N)$, whether the worker is a supervisor (SUPER), whether the job requires that the employee work fast $(F A S T)$, whether the worker is not allowed to make decisions $(N O D E C)$, whether the job requires that the worker not make mistakes $(M I S T K)$, job security (SECURITY), overtime work $(O V E R T)$, and training program availability $(T R A I N)$. These variables pertain to the worker's particular job, not broadly defined industrial and occupational groups. The availability of these job characteristic variables enables one to obtain estimates of job risk premiums that are not subject to the severe omitted variables bias that might be present if one included no other job attributes in the analysis.

The self-assessed danger variable ( $D A N$ $G E R$ ) also pertains to the individual's particular job. This job risk measure is the dummy variable for whether or not the worker's job exposes him to dangerous or unhealthy conditions. As indicated in table 2, just over half of the workers considered their jobs to be hazardous-a result that casts doubt on the common assumption that workers systematically under-assess job risks. Detailed examination of the hazards cited revealed that the risks are consistent with the individual's particular job. For example, temperature and humidity extremes are cited by a truck driver for a canning company, inadequate shoring is listed by a construction worker, and slippery floors and footing are cited by a manufacturing worker in the plastic products industry. Experimentation with variables pertaining to the number or type of hazards cited by the worker did not yield results superior to the $D A N G E R$ variable.

The principal advantage of this variable is that it is not an objective index but rather the subjective assessment of the risk, the magnitude that motivates individual behavior. To the extent that DANGER pertains to the individual's particular job, it is likely to be subject to less measurement error than would an average risk figure for the worker's industry or occupation. The principal limitation of the variable is that it does not reflect the differing severities and likelihoods of the hazards faced. Ideally, one would like the subjective probability assessments for a variety of health state outcomes, not a 0-1 dummy variable pertaining to the presence of hazards.

An alternative job hazard measure INJRATE will also be employed. This variable is the number of disabling injuries per million hours worked in 1969 for the worker's 3-digit (SIC code) industry. ${ }^{12}$ The industrial mix of the workers appears representative since the mean value of INJRATE is 15.93 , which is slightly greater than the manufacturing average of 14.8 but is less than nonmanufacturing injury rate levels, such as the 18.4 average for transportation and public utilities.

The relationship between $D A N G E R$ and INJRATE is summarized in table 3 . The last column of the table lists the fraction of workers in each INJRATE interval who consider their jobs dangerous. As expected, there is a strong positive relationship between the industry injury rate and the self-assessed danger variable. The failure of the $D A N G E R$ fraction to be a strictly increasing function of $I N J$ $R A T E$ throughout may be attributable to the fact that INJRATE pertains to the average hazard for the worker's industry group, not the risk posed by his particular job. Moreover, INJRATE reflects primarily safety hazards since health risks are not captured in the BLS

TABle 3.-DANGer Assessments AND THE INJURY RATE FOR THE WORKER'S INDUSTRY

\begin{tabular}{cccc}
\hline \hline INJRATE (IR) & Fraction & $\begin{array}{c}\text { DANGER=1 } \\
\text { Fraction }\end{array}$ & $\begin{array}{c}\text { Column 3 } \\
\text { Column 2 }\end{array}$ \\
\hline $0 \leqslant I R<5$ & .504 & .120 & .237 \\
$5 \leqslant I R<10$ & .178 & .076 & .426 \\
$10 \leqslant I R<15$ & .076 & .036 & .472 \\
$15 \leqslant I R<20$ & .077 & .041 & .534 \\
$20 \leqslant I R<25$ & .062 & .042 & .678 \\
$25 \leqslant I R<30$ & .070 & .046 & .657 \\
$30 \leqslant I R<35$ & .012 & .007 & .636 \\
$35 \leqslant I R<40$ & .015 & .009 & .600 \\
$40 \leqslant I R$ & .005 & .005 & 1.00 \\
\hline
\end{tabular}

\footnotetext{
${ }^{12}$ The source of this variable is the U.S. Bureau of Labor Statistics (BLS) (1972).
} 
statistics. In contrast, the hazards included in $D A N G E R$ are divided roughly evenly between health hazards (e.g., noise and noxious fumes) and safety hazards (e.g., slippery staircases).

\section{An Assessment of Compensating Earnings Differentials}

Recent analyses by Thaler and Rosen (1976) and by Smith (1976) have indicated that workers in occupations and industries with higher death rates receive additional wage compensation. ${ }^{13}$ The evidence in this section provides complementary findings for the two job risk variables DANGER and INJRATE in equations in which several other job characteristic variables are included in order to distinguish the influence of job risks per se, rather than job characteristics correlated with riskiness.

The two forms of equations to be estimated are

$$
E A R N G=\alpha+\sum_{k=1}^{m} \beta_{k} X_{k}+u,
$$

and

$$
\text { LOGEARNG }=\alpha^{\prime}+\sum_{k=1}^{m} \beta_{k}^{\prime} X_{k}+u^{\prime},
$$

where $\alpha$ and $\alpha^{\prime}$ are constant terms, $\beta_{k}$ and $\beta_{k}^{\prime}$ are coefficients, the $X_{k}$ 's are worker characteristics and job characteristics, and $u$ and $u^{\prime}$ are error terms. ${ }^{14}$ The linear form of the earnings equation implies a constant supply price per job characteristic unit, while the

\footnotetext{
${ }^{13}$ Smith (1976) utilized the death risk component of the INJRATE variable used here. His efforts to find positive and statistically significant wage effects for other variants of the BLS injury rate variable were unsuccessful. Thaler and Rosen (1976) employed the incremental death risk incurred by individuals in relatively hazardous occupations. As Lipsey (1976) noted, this variable compounds occupational risks and risks correlated with the personal characteristics of individuals in particular occupations. No job risk variable, including $D A N G E R$ and INJRATE, is ideal. Each has its own relative strengths and weaknesses. What is clear is that the similarity in the compensating differential results for each of these variables lends strong support to Adam Smith's claim that more hazardous jobs will command premiums in the labor market.

${ }^{14}$ The earnings equation can be viewed as part of a larger recursive system. An attempt was made to estimate the simultaneous relationship between earnings and job hazards using two-stage least squares. The results were consistent with the recursive formulation. See Viscusi (1976).
}

semi-logarithmic form implies a rising supply price per characteristic unit. The procedure of viewing worker earnings as being dependent on the attributes of his job in effect involves the estimation of a hedonic earnings function, which is econometrically similar to the hedonic price index analysis. ${ }^{15}$

The regression results are reported in table 4. Equations (1) and (3) include DANGER in the $E A R N G$ and LOGEARNG regressions, respectively, while equations (2) and (4) include the objective hazard index INJRATE. Equations (2) and (4) omit the industry dummy variable list since INJRATE is the industry injury rate matched to the workers in the sample using their industry responses.

The coefficients for the first ten variables in the equations, which represent personal and enterprise characteristics, reflect familiar patterns of influence. Better educated workers earn more, as do those who belong to a union. Females and workers with health impairments earn less. The magnitudes of the effects often are less than are usually found since much of the impact of these exogenous variables is indirect via the job characteristic variables, such as whether the worker is a supervisor. ${ }^{16}$

The two job risk variables each reflect positive and statistically significant earnings premiums for hazardous work. ${ }^{17}$ The results in equation (1) indicate that workers on jobs perceived as being dangerous earn an annual earnings premium of $\$ 375$. Although this amount represents only $5.5 \%$ of workers' mean earnings of $\$ 6,810$, the low level of compensation is not implausible in view of the large percentage of workers $(52.2 \%)$ who claim that their jobs expose them to dangerous or unhealthy conditions.

An instructive check on the plausibility of the level of the job risk premium is to compare its magnitude with the average premium implied by INJRATE. Equation (2) indicates that workers receive an additional $\$ 26$ for a one point increase in the frequency of disabling

\footnotetext{
${ }^{15}$ For a survey of the hedonic price index literature, see Griliches (1971).

${ }^{16}$ The reduced form estimates are more comparable to the results in the human capital literature.

${ }^{17}$ Throughout this analysis, references to statistical significance refer to tests at the $5 \%$ level. The value of $t_{95}$ for a one-tailed $t$-test with an infinite sample size is 1.645 .
} 
TABLE 4.-EARNG AND LOGEARNG REGRESSION RESULTS

\begin{tabular}{|c|c|c|c|c|}
\hline \multirow{3}{*}{$\begin{array}{l}\text { Independent } \\
\text { Variables }\end{array}$} & \multicolumn{4}{|c|}{ Coefficients and Standard Errors } \\
\hline & \multicolumn{2}{|c|}{$E A R N G$} & \multicolumn{2}{|c|}{ LOGEARNG } \\
\hline & 1 & 2 & 3 & 4 \\
\hline$A G E$ & $\begin{array}{r}+138.22 \\
(45.50)\end{array}$ & $\begin{array}{r}+163.74 \\
(44.40)\end{array}$ & $\begin{array}{c}+.025 \\
(.0072)\end{array}$ & $\begin{array}{c}+.030 \\
(.0070)\end{array}$ \\
\hline$A G E \times A G E$ & $\begin{array}{c}-1.63 \\
(0.53)\end{array}$ & $\begin{array}{r}-1.96 \\
(0.51)\end{array}$ & $\begin{array}{c}-.28 \mathrm{E}-3 \\
(.083 \mathrm{E}-3)\end{array}$ & $\begin{array}{c}-.34 \mathrm{E}-3 \\
(.082 \mathrm{E}-3)\end{array}$ \\
\hline$F E M A L E$ & $\begin{array}{r}-2585.9 \\
(278.9)\end{array}$ & $\begin{array}{r}-2809.3 \\
(244.8)\end{array}$ & $\begin{array}{c}-.507 \\
(.044)\end{array}$ & $\begin{array}{c}-.534 \\
(.039)\end{array}$ \\
\hline$B L A C K$ & $\begin{array}{c}-382.38 \\
(276.19)\end{array}$ & $\begin{array}{r}-429.00 \\
(269.54)\end{array}$ & $\begin{array}{c}-.063 \\
(.044)\end{array}$ & $\begin{array}{c}-.067 \\
(.043)\end{array}$ \\
\hline$E D U C$ & $\begin{array}{r}+128.84 \\
(33.34)\end{array}$ & $\begin{array}{r}+136.14 \\
(32.76)\end{array}$ & $\begin{array}{c}+.024 \\
(.0053)\end{array}$ & $\begin{array}{l}+.025 \\
(.0052)\end{array}$ \\
\hline$H E A L T H$ & $\begin{array}{r}-194.91 \\
(93.88)\end{array}$ & $\begin{array}{r}-168.92 \\
(93.14)\end{array}$ & $\begin{array}{r}-.019 \\
(.015)\end{array}$ & $\begin{array}{c}-.017 \\
(.015)\end{array}$ \\
\hline SINGLE & $\begin{array}{r}-1088.6 \\
(343.9)\end{array}$ & $\begin{array}{r}-981.16 \\
(328.75)\end{array}$ & $\begin{array}{r}-.231 \\
(.054)\end{array}$ & $\begin{array}{c}-.210 \\
(.052)\end{array}$ \\
\hline$S I Z E$ & $\begin{array}{c}+0.233 \\
(0.119)\end{array}$ & $\begin{array}{r}+0.305 \\
(0.104)\end{array}$ & $\begin{array}{r}+.25 E-4 \\
(.19 E-4)\end{array}$ & $\begin{array}{r}+.38 E-4 \\
(.16 E-4)\end{array}$ \\
\hline UNION & $\begin{array}{c}+543.07 \\
(206.88)\end{array}$ & $\begin{array}{r}+645.05 \\
(196.53)\end{array}$ & $\begin{array}{r}+.109 \\
(.033)\end{array}$ & $\begin{array}{r}+.113 \\
(.031)\end{array}$ \\
\hline TENURE & $\begin{array}{r}+12.40 \\
(11.28)\end{array}$ & $\begin{array}{l}+6.25 \\
(10.87)\end{array}$ & $\begin{array}{l}-.13 \mathrm{E}-3 \\
(1.78 \mathrm{E}-3)\end{array}$ & $\begin{array}{c}-.0015 \\
(.0017)\end{array}$ \\
\hline$D A N G E R$ & $\begin{array}{c}+374.82 \\
(177.67)\end{array}$ & - & $\begin{array}{c}+.055 \\
(.028)\end{array}$ & - \\
\hline INJRATE & - & $\begin{array}{c}+26.37 \\
(10.14)\end{array}$ & - & $\begin{array}{r}+.0040 \\
(.0016)\end{array}$ \\
\hline$S U P E R$ & $\begin{array}{r}+372.24 \\
(193.89)\end{array}$ & $\begin{array}{r}+414.69 \\
(191.43)\end{array}$ & $\begin{array}{r}+.032 \\
(.031)\end{array}$ & $\begin{array}{c}+.043 \\
(.030)\end{array}$ \\
\hline$F A S T$ & $\begin{array}{r}+519.54 \\
(189.64)\end{array}$ & $\begin{array}{r}+460.82 \\
(184.22)\end{array}$ & $\begin{array}{r}+.072 \\
(.030)\end{array}$ & $\begin{array}{c}+.063 \\
(.029)\end{array}$ \\
\hline NODEC & $\begin{array}{r}-121.78 \\
(83.85)\end{array}$ & $\begin{array}{r}-146.67 \\
(82.38)\end{array}$ & $\begin{array}{r}-.016 \\
(.013)\end{array}$ & $\begin{array}{c}-.021 \\
(.013)\end{array}$ \\
\hline$M I S T K$ & $\begin{array}{r}-127.91 \\
(85.31)\end{array}$ & $\begin{array}{r}-140.29 \\
(82.79)\end{array}$ & $\begin{array}{c}-.023 \\
(.013)\end{array}$ & $\begin{array}{r}-.027 \\
(.013)\end{array}$ \\
\hline SECURITY & $\begin{array}{r}+521.27 \\
(177.90)\end{array}$ & $\begin{array}{r}+496.28 \\
(172.06)\end{array}$ & $\begin{array}{c}+.093 \\
(.028)\end{array}$ & $\begin{array}{r}+.097 \\
(.027)\end{array}$ \\
\hline$O V E R T$ & $\begin{array}{r}+170.12 \\
(67.41)\end{array}$ & $\begin{array}{r}+191.76 \\
(64.66)\end{array}$ & $\begin{array}{r}+.032 \\
(.011)\end{array}$ & $\begin{array}{c}+.037 \\
(.010)\end{array}$ \\
\hline$T R A I N$ & $\begin{array}{c}+362.08 \\
(201.14)\end{array}$ & $\begin{array}{r}+519.59 \\
(193.27)\end{array}$ & $\begin{array}{r}+.059 \\
(.032)\end{array}$ & $\begin{array}{r}+.099 \\
(.031)\end{array}$ \\
\hline $\begin{array}{l}\text { Other } \\
\text { Variables }\end{array}$ & LIST1 & LIST2 & LIST1 & LIST2 \\
\hline $\begin{array}{l}R^{2} \\
\text { S.E.E. }\end{array}$ & $1813.5^{.641}$ & 1836.6 & $\begin{array}{l}.698 \\
.286\end{array}$ & $\begin{array}{l}.669 \\
.291\end{array}$ \\
\hline
\end{tabular}

Note: Each equation also includes the variable lists $L O C A T E$ and $J O B$. Equations (1) and (3) also include industry dummy variable list INDUSTRY, which is omitted from the equations including INJRATE since this job risk index was constructed using information regarding the worker's industry. 
work injuries per million hours worked. Since the average value of INJRATE is 15.93 , the mean level of annual earnings compensation for injuries is $\$ 420$. This amount is only $\$ 45$ more than was implied by the DANGER variable-a discrepancy that is "well within the bounds of error. Both job hazard variables indicate an average level of compensation for risky jobs of about $\$ 400$ annually in 1969.

The other job characteristic variables included in the regressions serve two functions. First, they control for a variety of job attributes, thus reducing the bias in the job hazard variables' coefficients. Second, they provide additional tests of the validity of the theory of compensating differentials.

The coefficients associated with these variables reflect the expected patterns of influence. Supervisors (SUPER) are paid more, as are employees whose jobs require them to work fast $(F A S T)$, who work overtime (OVERT), or who work for enterprises with training programs $(T R A I N)$. Workers who do not make decisions (NODEC) and whose jobs require them not to make mistakes (MISTK) tend to be paid somewhat less, which is consistent with the lighter tasks and lower level assembly line work associated with these characteristics. The only variable with a sign opposite of what one might expect on the basis of the compensating differentials analysis is SECURITY. However, the higher earnings of individuals with job security is quite consistent with the greater security associated with upper level blue collar positions. This variable thus may be capturing primarily the relative ranking of the worker's job rather than any particular job attribute that is not appropriately compensated.

\section{The Role of Worker Assets}

The second major prediction of the conceptual analysis is that the optimal job risk will necessarily decrease with the worker's wealth, provided that certain mild restrictions on the worker's preferences and employment opportunities are imposed. The validity of this result cannot be tested using the SWC data since the survey did not include a worker wealth variable. One can, however, use the 1969 data from the National Longitudinal Survey of
Mature Men in conjunction with the 1969 BLS industry injury rates to ascertain whether there is any systematic relationship between the injury rate of the worker's industry and his wealth.

The sample to be considered consists of 1,932 males who were 45-59 years old when the survey began in 1966 and had a mean age of 53.7 in 1969. The dependent variable for the analysis is INJRATE. The independent variables used either have the same definitions as do the SWC variables $(A G E, E D U C)$ or else are self-explanatory (NONWHITE). The explanatory variable of greatest interest is ASSETS, which is the worker's net asset position. ASSETS has a mean value of $\$ 21,717$.

Table 5 reports the regression results. ASSETS has a statistically significant coefficient with the expected sign. The magnitude of the effect is rather small, however, since these results imply that the elasticity of the industry injury frequency rate with respect to worker wealth is only -0.011 . This finding is likely to understate the wealth effect since it captures the influence of wealth only on the worker's choice of an industry. One might expect that much of the wealth effect would be reflected in the individual's occupation or particular job within the inüustry. It should be noted that the direction rather than the magnitude of the impact is of central concern since the negative elasticity estimate provides additional support of the validity of the overall conceptualization of individual choice.

TABLE 5.-REGRESSION OF INJRATE ON ASSETS AND OTHer PERTINent VARIAbles

\begin{tabular}{lc}
\hline \hline$A G E$ & -0.018 \\
& $(0.052)$ \\
NONWHITE & -1.38 \\
& $(0.499)$ \\
EDUC & -0.629 \\
& $(0.063)$ \\
ASSETS & $-0.81 \mathrm{E}-5$ \\
$R^{2}$ & $(0.38 \mathrm{E}-5)$ \\
S.E.E. & 0.090 \\
$F$ & 8.91 \\
\hline
\end{tabular}

Note: Other variables included were an area unemployment variable, 3 regional dummies, 1 SMSA dummy, union membership, and health status. The sample size was 1,932 . 


\section{Conclusions}

The conceptual analysis of individual choice among potentially hazardous jobs indicated that the optimal job risk for a worker should be negatively related to his wealth and that workers will demand earnings premiums for hazardous jobs - a result originally articulated by Adam Smith. The empirical analysis provided strong support for these conceptual results. The annual earnings premium for job hazards averaged $\$ 400$ in 1969 . This value is not particularly low in view of the large number of workers who viewed their jobs as being hazardous. The injury rate for an employee's industry also was negatively related to worker assets, although the effect was not as large as one would expect if more appropriate data were available to evaluate the magnitude of this relationship.

\section{REFERENCES}

Griliches, Zvi (ed.), Price Indexes and Quality Change (Cambridge: Harvard University Press, 1971).

Lipsey, Robert, "Comments on the Value of Saving a Life: Evidence from the Labor Market," in N. Terleckyz (ed.), Household Production and Consumption, NBER Studies in Income and Wealth no. 40 (New York: Columbia University Press, 1976), 301-302.
Oi, Walter, "An Essay on Workmen's Compensation and Industrial Safety," in Supplemental Studies for the National Commission on State Workmen's Compensation Laws (Washington, D.C.: U.S. Government Printing Office, 1973), 41-106.

Reder, Melvin, "Wage Differentials: Theory and Measurement," in Aspects of Labor Economics (Princeton: Princeton University Press, 1962), 257-311.

Smith, Adam, The Wealth of Nations (New York: Modern Library, 1937).

Smith, Robert, The Occupational Safety and Health Act: Its Goals and Its Achievements (Washington, D.C.: American Enterprise Institute, 1976).

Thaler, Richard, and Sherwin Rosen, "The Value of Saving a Life: Evidence from the Labor Market," in N. Terleckyz (ed.), Household Production and Consumption, NBER Studies in Income and Wealth no. 40 (New York: Columbia University Press, 1976), 265-298.

U.S. Bureau of Labor Statistics, Handbook of Labor Statistics (Washington, D.C.: U.S. Government Printing Office, 1972).

University of Michigan Institute for Social Research, Survey of Working Conditions, SRC Study no. 45369 (Ann Arbor: University of Michigan Social Science Archives, 1975).

Viscusi, W. Kip, Employment Hazards: An Investigation of Market Performance, Ph.D. dissertation, Harvard University, 1976. "Job Hazards and Worker Quit Rates: An Analysis of Adaptive Worker Behavior," International Economic Review (forthcoming).

Weiss, Yoram, "The Wealth Effect in Occupational Choice," International Economic Review 17 (June 1976), 292-307. 